\title{
Exploring Knowledge Types as Determinants of Preventive Behaviour and Diabetes Risk among Older People
}

\author{
Muriela Páduaa \\ João M. Santos $b, a^{*}$ \\ Hugo Hortac, a

\begin{abstract}
a Center for Innovation, Technology and Policy Research IN+, Instituto Superior Técnico Technical University of Lisbon, Portugal; muriela.padua@ist.utl.pt b Instituto Universitário de Lisboa (ISCTE-IUL), Centro de Investigação e Intervenção Social (CIS-IUL), Lisbon, Portugal joao_marques_santos@iscte.pt c Division of Policy, Administration \& Social Sciences Education, Faculty of Education The University of Hong Kong, Hong Kong SAR, China; horta@hku.hk
\end{abstract}

\section{Doi:10.5901/mjss.2016.v7n5p249}

\section{Abstract}

\begin{abstract}
The association between education and risk of getting diabetes is established in the context of primary prevention. Yet, the determinants that can account for this association are under-analysed, particularly regarding older people living in cities. This article addresses this gap in an explorative study $(n=356)$, focusing in older people in vulnerable urban areas of Lisbon, Portugal. The analysis focuses on data drawn from interviews and surveys analysed by regression methods. The data includes variables accounting for socio-demographic condition, risk perception, risks of having diabetes based on FINDRISC scores, and habits related to modifiable risk factors. The analysis suggests that: 1) the role of education (a formal knowledge type) is connected with healthy lifestyles, underlining the role of values and social rules; 2) risk perceptions and factual knowledge per se do not seem to be the most adequate to foment behavioural change in older people; and 3) a knowledge typology is proposed for a first-step conceptual framework applied to the older, lower educated, urban populations. The article concludes that education's social dimension has a strong effect on risk of developing diabetes than knowledge per se. This highlights the need of considering other aspects of preventing disease beyond the more often used traditional strategies.
\end{abstract}

Keywords: diabetes, primary health care, education, social determinants; risk perception, older people

\section{Introduction}

Diabetes is a disease that is increasingly prevalent in large urban areas (Holt, 2012; Zhang et al., 2012). Concurrently, studies identify older people in urban environments as those with the highest risk proportion of developing diabetes of any age group (Kirsch, Educational Testing Service, \& And Others, 1993; White, 2008); They are also the age group with the lowest formal education levels (Baker et al., 2007; Howard, Sentell, \& Gazmararian, 2006; Kim, 2009; Kripalani et al., 2006; Lee, Bender, Ruiz, \& Cho, 2006; Sudore et al., 2006). The combination of high risk and low education levels represents a major challenge for these populations when it is known these impact prevention behaviours (Ezzati \& Riboli, 2012; Gornick, 2003; Greef, Deforche, Tudor-Locke, \& Bourdeaudhuij, 2010).

In the context of prevention, studies have suggested a relation between education and health outcomes (Schillinger, Barton, Karter, Wang, \& Adler, 2006). These studies focused mostly on secondary and tertiary intervention but less is known about the role of education in primary care intervention within the context of diabetes, since the determinants of the association between education and prevention and health outcomes are still underexplored. Indeed there is no systematic empirical exploration of the determinants that mediate the relation between education and risk of getting diabetes. Moreover, although some studies have been carried out on how risk perception/knowledge types affect awareness in the context of primary intervention these studies do not focus on the older population (Hivert, Warner, Shrader, Grant, \& Meigs, 2009).

These studies also tend to be focused on intermediate variables such as awareness of diabetes per se rather than examining the impact of the later on the preventive behaviours and risk of getting diabetes. As such there is a lack of typologies on knowledge for this type of population and how these relate with risk perceptions. Furthermore, while there have been studies that examine the determinants that mediate the relationship between education and risk 
outcomes/preventive behaviour in secondary and tertiary intervention, these focus on people that are already ill (Morris, MacLean, \& Littenberg, 2006). The focus on knowledge in these studies is thus very practical. It is about how to do things. But in primary intervention contexts, it might be the case that this 'practical' knowledge on outcomes/preventive behaviours may not work the same way (Alberti, Zimmet, \& Shaw, 2007; American Diabetes Association, 2013; Nutbeam, 2000; Risérus, Willett, \& Hu, 2009). Therefore, there is a lack of understanding on how education may account for change of practices or the risk of getting diabetes.

Given the aforementioned knowledge gap, there is a need to better comprehend what types of knowledge (i.e. determinants) 1) reduce the risks and 2) lead to activities that contribute to the reduction of risk of having diabetes. In order to deal with this knowledge-gap, this research starts by identifying the three types of knowledge found in the literature as determinants that may have a role in improving preventive behaviours and reducing risk of having diabetes.

Education (as formal knowledge): in attempting to deepen the understanding of the association between education and poor health outcomes in the context of primary intervention, studies have examined the role of genetic factors, anthropometric data and lifestyle effects (Martín, Nieto, Ruiz, \& Jiménez, 2008; Mayer-Davis \& Costacou, 2001; Wikner, Gigante, Hellénius, de Faire, \& Leander, 2013). For example, research has shown that education correlates negatively with $70 \mathrm{HbA} 1 \mathrm{c}$-levels of glycaemia in the blood (Tang, Pang, Chan, Yeung, \& Yeung, 2008). Descriptive evidence shows that limited education levels can increase the risk of poor health outcomes (including mortality rate) in the context of primary intervention (Sabates, Feinstein, \& Britain, 2004). A recent study by the Portuguese Ministry of Health (Boavida et al., 2012) has shown that illiterates have a greater incidence of having diabetes than literates. However, despite calls for a better understanding of the association between education and poor health outcomes in the context of primary intervention, this association remains poorly explained (Alberti et al., 2007; American Diabetes Association, 2013; Nutbeam, 2000; Risérus et al., 2009).

Factual knowledge: in the context of primary intervention people are usually unaware of basic facts relative to diseases in general, and in particular, to non-communicable diseases (DiLorenzo et al., 2006; Maty \& Tippens, 2011). This is particularly relevant for poorly educated populations (Maina, Ndegwa, Njenga, \& Muchemi, 2011). It is expected that factual knowledge has a critical role as a first condition to promote preventive practices (Berkman, Sheridan, Donahue, Halpern, \& Crotty, 2011). Two studies are helpful in illuminating this argument. A study combining a multimedia campaign focused on a population of 1.94 million in Qingdao province in China combined with a diabetes risk score questionnaire, evidenced that after the campaign the awareness of diabetes risk factors increased substantially (Zhang et al., 2012). One other study by Maina et al (2011) show that populations with good factual knowledge of diabetes have better practices than people with poor knowledge of diabetes. In all these studies, it became clear that practices fostering factual knowledge are relevant in vulnerable communities with high risk diabetes incidence and low levels of literacy.

Risk perception: studies show that risk perceptions are related to risk awareness (Farmer, Levy, \& Turner, 1999). Risk perceptions matter in different ways according to the type of behaviours, namely whether they are ongoing or repeated (e.g., condom use) (Reid \& Aiken, 2011), intermittent (e.g., vaccines) (Brewer et al., 2007; Nexøe, Kragstrup, \& Søgaard, 1999) and new (e.g., a new colonoscopy and new habits) (Dillard, Ferrer, Ubel, \& Fagerlin, 2012; Nexøe et al., 1999). The literature tends to suggest an association between risk perception and education in relation to primary prevention (Brewer et al., 2007). Yet, in some contexts neither risk perception nor education matter (Maswanya et al., 1999). Although there is some evidence, it is far from being conclusive, while the general idea that risk perception and education matter for preventive behaviours concerning health continues to require validation. Moreover, little is known on the association between risk perception, knowledge and health outcomes.

In sum, the purpose of this study is threefold. It will examine whether there is an association between formal education, factual knowledge and risk perceptions and the risk of getting diabetes (Health outcomes). Second, the study will examine whether education, risk perceptions and factual knowledge is associated with modifiable risk behaviours (Prevention). Third, a typology of factual knowledge is proposed and tested versus formal education levels to better understand the role of knowledge on diabetes primary prevention.

\section{Methods}

This is a cross-sectional observational study. Our sample consists of 356 subjects, mostly comprised of older people ( $M=62,25 ; S D=15,64)$, who were recruited during a diabetes screening project conducted by Santa Casa da Misericórdia (a charity Portuguese organization of hospitals and health centres who have carried out prevention/education programs for older populations for several years under a program called "Proximate Health"). Every subject who underwent the screening procedure was interviewed while waiting. The majority of the subjects had a basic education as the highest educational attainment: $16 \%$ of the subjects had no education, $73 \%$ had a basic education (ISCED97 levels 0 through 2) 
and $11 \%$ had a secondary or higher education (ISCED97 levels 3 through 6). Our sample is comprised of diabetics and non-diabetics, the latter with varying degrees of risk. Due to the nature of the questions, individuals who were already diabetic were excluded from the final analysis, as the questions pertaining to risk perception were not applicable to them. 64 subjects were excluded from the analysis based on this criteria.

In order to assess the objective risk of the subjects developing diabetes, FINDRISC was used by the nurses that were conducting the screening project. FINDRISC is a medical scale which is used to classify subjects according to their likelihood of developing diabetes on a 5-point scale. The nurses asked additional questions regarding preventive behaviours; first, degree of physical activity, coded as 5 levels depending on its frequency: "Sedentary" for none or little"; "Light" for 1-3 days per week; "Moderate" for 3-5 days per week; "Intense" for 6-7 days per week; and "Very Intense" for double daily training sessions. Amount of daily meals, coded as 3 points: 5-6 meals, 4 meals, or 3 meals or less; daily fruit intake, coded as 3 points: more than 5 units, 3 to 5 units, 2 or less units; daily vegetable intake, coded as 3 points: more than 5 units per day, 3 to 5 units, and 2 or less units; and daily water intake, coded as 4 points: less than 0,5 litres, between 0,5 and 1 litre, between 1 and 1,5 litres, and more than 1,5 litres.

To the data on subject's objective risk and prevention habits, socio-demographic data and assessment of subjects in terms of risk perception and knowledge with regards to diabetes is added. The procedures used to develop the scales that were coupled with FINDRISC were as follows: the subjects prior to being screened for diabetes were surveyed. They were asked if they felt they were at risk, and their perceived risk was evaluated on a scale from 1 to 5 . Demographic data was also collected for each subject, most notably the education level. 14 questions concerning knowledge on diabetes were included. Regarding these questions, a knowledge scale was implemented where the following procedures were used to code correct and incorrect answers: Correct answers increased the total questionnaire score by 1; incorrect answers subtracted 1 to the total score; and "don't know" answers yielded no shift in the total score (since absence of knowledge is different from incorrect knowledge).

In relation to the knowledge scale, a team of nine nurses and two nutritionists from Santa Casa da Misericórdia were extensively consulted. Each of the nurses has seen more than 4,000 patients of this age and their feedback throughout the design of the survey was critical. Existing scales were analysed, and it was realized that they have three levels (extreme complications of diabetes, pathophysiology, and risk factors). The survey questions focused on risk factors and behaviours associated with diabetes, their limited knowledge on pathophysiology of the disease and extreme complications associated with diabetes (Boavida et al., 2012), with simple true/false questions (for example, "Diabetes can lead to blindness"). All these are standard facts regarding diabetes. Also included were questions of different levels of difficulty to distinguish people with different knowledge levels.

\section{Results}

Table 1 assesses the predictor effects of education, risk perception, and factual knowledge on risk scores. The analysis shows that people with higher educational levels have a statistically significant negative effect on risk score in the order of $38 \%$ in the risk score. This implies that people with higher levels of formal education tend to have a lesser risk of having diabetes when compared with people with no education. The risk score of people with basic education levels, however, are undistinguished from that of those without education. On the other hand, the higher the risk perception, the greater is the risk score. For every single point increase of risk perception there is an increase in 0.322 in the risk score. Factual knowledge does not seem to impact on risk score. In terms of the control variables, only health screening is significant. Health screening is a binary variable indicating if in the last reference year people had at least one doctor appointment. As expected, there is a positive association between people going to the doctor and risk score (42\% greater risk score than the ones who did not). However, this result can be misleading since people that tend to go to the doctor are people that already have a large risk score (Nabalamba \& Millar, 2007). Gender and having in the family people with diabetes (also coded as a binary variable, indicating on whether they have or not, irrespective of degree) have no impact on risk scores.

Table 1: Determinant effects on risk score

\begin{tabular}{lc}
\hline Variables & Risk Score \\
\hline Gender (Male) & $-0,159$ \\
& $(0,148)$ \\
Education (Secondary and Higher) & $-0,801 * *$ \\
& $(0,381)$ \\
Education (Basic) & $-0,156$ \\
& $(0,296)$ \\
\hline
\end{tabular}




\begin{tabular}{|c|c|}
\hline Knowledge on Diabetes & $\begin{array}{c}0,043 \\
(0,030)\end{array}$ \\
\hline Diabetic Family Members & $\begin{array}{c}0,229 \\
(0,144)\end{array}$ \\
\hline Health Screening & $\begin{array}{c}1,110 * * * \\
(0,230)\end{array}$ \\
\hline Risk Perception & $\begin{array}{l}0,322 * \\
(0,176)\end{array}$ \\
\hline Education (Secondary and Higher) * Risk Perception & $\begin{array}{l}-0,108 \\
(0,213)\end{array}$ \\
\hline Education (Basic) * Risk Perception & $\begin{array}{l}-0,134 \\
(0,181)\end{array}$ \\
\hline$F(9,205)$ & 7,882 *** \\
\hline Adjusted R-Squared & 0,224 \\
\hline Observations & 215 \\
\hline
\end{tabular}

Table 2 shows the association between risk perceptions, education and factual knowledge and preventive behaviours. Drawing on the literature on preventive behaviours concerning diabetes, a regression analysis is run between the proposed determinants and modifiable risk behaviours, including physical activity (Alberti et al., 2007), number of daily meals (Salehi et al., 2010), daily fruit intake (Salehi et al., 2010), daily vegetables intake (Salehi et al., 2010) and daily water intake (Robben, Knoers, \& Deen, 2006). The results indicate that people with higher levels of education practice more physical activity, which is aligned with studies linking socioeconomic level to physical activity practice (Ford et al., 1991). Those with secondary and higher education engage $58 \%$ more in physical activity, and those with basic education $29 \%$ more when comparing with those that lack education. Those with secondary and higher education also have a $28 \%$ greater intake of water than those without education, while no statistical significant differences were found between those with basic education and no education. Education levels do not seem to relate number of daily meals, and daily intake of fruit and vegetables. Risk perception is also a predictor of some modifiable risk behaviours. The results indicate that for each unit increase in risk perception leads to a decrease of 0.068 physical activities and a 0.102 decrease in the number of daily meals. No association is found between risk perception and daily fruit, vegetables, and water intake. Factual knowledge is not a predictor of modifiable risk behaviours, a result which has been replicated in some studies (Maswanya et al., 1999), and which will be discussed further ahead. In terms of the control variables, having diabetic family members only impact positively on the daily water intake, while health screening associates positively with the number of daily meals, fruit and vegetable intake, but negatively related to the daily intake of water.

Table 2: Determinant effects on preventive behaviors

\begin{tabular}{lccccc}
\hline Variables & $\begin{array}{c}\text { Physical } \\
\text { Activity }\end{array}$ & $\begin{array}{c}\text { Number of Daily } \\
\text { Meals }\end{array}$ & $\begin{array}{c}\text { Daily Fruit } \\
\text { Intake }\end{array}$ & $\begin{array}{c}\text { Daily Vegetables } \\
\text { Intake }\end{array}$ & $\begin{array}{c}\text { Daily Water } \\
\text { Intake }\end{array}$ \\
\hline Gender (Male) & $0,218^{* *}$ & $-0,361 * *$ & 0,016 & 0,107 & 0,134 \\
& $(0,105)$ & $(0,116)$ & $(0,088)$ & $(0,071)$ & $(0,141)$ \\
Education (Secondary and Higher) & $0,690 * *$ & 0,316 & 0,166 & 0,104 & $0,623 * *$ \\
& $(0,218)$ & $(0,241)$ & $(0,184)$ & $(0,149)$ & $(0,294)$ \\
Education (Basic) & $0,342 *$ & 0,370 & $-0,082$ & $-0,033$ & 0,393 \\
Knowledge on Diabetes & $(0,180)$ & $(0,199)$ & $(0,152)$ & $(0,123)$ & $(0,243)$ \\
& $-0,013$ & $-0,007$ & $-0,024$ & 0,007 & $-0,006$ \\
Diabetic Family Members & $(0,021)$ & $(0,023)$ & $(0,017)$ & $(0,014)$ & $(0,028)$ \\
& 0,102 & $-0,057$ & 0,099 & $-0,040$ & $0,288 * *$ \\
Health Screening & $(0,102)$ & $(0,112)$ & $(0,086)$ & $(0,069)$ & $(0,137)$ \\
& 0,136 & $0,359 * *$ & $0,297 * *$ & $0,202 *$ & $-0,508 * *$ \\
Risk Perception & $(0,163)$ & $(0,180)$ & $(0,137)$ & $(0,111)$ & $(0,219)$ \\
& $-0,068 * *$ & $-0,102 * *$ & $-0,008$ & $-0,029$ & $-0,053$ \\
F(7,208) & $(0,029)$ & $(0,032)$ & $(0,025)$ & $(0,020)$ & $(0,040)$ \\
Adjusted R-Squared & $2,898^{* * *}$ & $4,159 * * *$ & 1,676 & 1,305 & $2,218 * *$ \\
Observations & 0,058 & 0,093 & 0,022 & 0,010 & 0,038 \\
\hline
\end{tabular}

Notes. A General Linear Model with fixed factors (coded as dummies) and covariates is shown. Standard errors are in parenthesis. ${ }^{*} p<0,1 ;{ }^{* *} p<0,05 ;{ }^{* *} p<0,01$. 
Based on Table 1 and 2 results, an analysis is performed to assess to what extent the proposed determinants are correlated. To ascertain this correlation, bivariate correlations between the proposed determinants are run, finding that there are no significant correlations (Table 3). Even if the correlations were significant the strength of the correlations would be very weak.

Table 3: Bivariate correlations

\begin{tabular}{lccc}
\hline Variables & Risk Perception & Diabetes Knowledge & Education \\
\hline Risk Perception & - & & \\
Diabetes Knowledge & 0,090 & - & \\
Education & 0,089 & 0,074 & - \\
\hline${ }^{*} p<0,1 ;{ }^{* *} p<0,05 ;{ }^{* \star *} p<0,01$. & &
\end{tabular}

The lack of association between factual knowledge with both risk score and modifiable risk behaviours (Table 1 and 3) combined with the literature suggestion that factual knowledge could impact risk scores (Berkman et al., 2011), led to a further exploratory analysis. This analysis aims to better understand the association between educational level and selected dimensions of factual knowledge (Table 4). The analysis shows that no differences were found regarding educational level in relation to the risks of extreme complications of diabetes $(F(2,353)=1,280, p=0,278)$ or to the risk factors associated with diabetes $(F(2,353)=1,531, p=0,218)$. Based on the interviews with the subjects, it was expected that the population with no education or a basic level of education were well aware that diabetes can cause death or the amputation of a leg. All the subjects scored high on the perception of risks for the extreme complications of diabetes. Inversely, all the subjects scored low on risk factors, independent of education level. It was in the risk perceptions associated with knowledge on pathophysiology that differences between those with more education and those with less education or without an education emerged $(F(2,353)=4,190, p<0,05)$. These results suggest that education level plays some role in risk perceptions concerning diabetes but that this role is somewhat limited and that knowledge gaps remain even amongst the more educated (mainly with regard to prevention). This confirms the results of Table 3 regarding an overall lack of correlation between education levels and factual knowledge.

Table 4: Dimensions of factual knowledge among different education group strata

\begin{tabular}{|c|c|c|c|}
\hline Variable & [I] Education & {$[J]$ Education } & $P$-value* \\
\hline \multirow{6}{*}{ Factual knowledge on extreme complications of diabetes } & \multirow{2}{*}{ No education } & Basic & 0.716 \\
\hline & & Secondary of higher & 0.231 \\
\hline & \multirow{2}{*}{ Basic } & No education & 0.716 \\
\hline & & Secondary or higher & 0.385 \\
\hline & \multirow{2}{*}{ Secondary or higher } & No education & 0.231 \\
\hline & & Basic & 0.385 \\
\hline \multirow{6}{*}{ Factual knowledge on pathophysiology } & \multirow{2}{*}{ No education } & Basic & 0.079 \\
\hline & & Secondary or higher & 0.006 \\
\hline & \multirow{2}{*}{ Basic } & No education & 0.079 \\
\hline & & Secondary or higher & 0.139 \\
\hline & \multirow{2}{*}{ Secondary or higher } & No education & 0.006 \\
\hline & & Basic & 0.139 \\
\hline \multirow{6}{*}{ Factual knowledge associated with risk factors } & \multirow{2}{*}{ No education } & Basic & 0.775 \\
\hline & & Secondary or higher & 0.229 \\
\hline & \multirow{2}{*}{ Basic } & No education & 0.775 \\
\hline & & Secondary or higher & 0.337 \\
\hline & \multirow{2}{*}{ Secondary or higher } & No education & 0.229 \\
\hline & & Basic & 0.337 \\
\hline
\end{tabular}

* Tukey's HSD test for pair-wise comparisons was used. Note: [l] Education and [J] Education indicate which pair is being compared. 


\section{Discussion}

This is to our knowledge one of the first studies that empirically examines the knowledge type determinants of risk of getting diabetes and preventive behaviours in an older urban population and within a primary prevention context. Based on these findings, suggestions are presented that can be useful to better explore the components that can account for the association between knowledge types, risk perception, preventive behaviour and health outcomes for this type of population.

As expected there is a negative and significant correlation between educational level and the risk of getting diabetes. It is found that education is relevant for preventive behaviours as well. The fact that greater education levels are associated with risk and preventive behaviours is not new (Sabates et al., 2004). Also, that knowledge itself is not enough to account for preventive behaviours or health outcomes is not new either (Edwards, Wood, Davies, \& Edwards, 2012; Paasche-Orlow \& Wolf, 2007). But this study's results in the context of primary intervention concerning an older urban population suggests that there is a need to find new ways to account for the association between education and health outcomes for this population. This study shows that the association between education and risk and preventive behaviours is not self-explanatory, but is mostly explained by the socialization that formal education provides in terms of physical education, physical activity and healthier lifestyles.

The benefits of physical education are well documented in the literature (Bailey, 2006). They often refer a combination of physical, social, affective and cognitive factors that are learned and become ingrained throughout the formal education learning experience (Bailey et al., 2009). These studies point out that the more an individual is exposed to places of formal learning (school, university) the more is the likelihood of practicing and engaging in physical activities and healthy behaviours, independent of which they are part of the formal curricula or not.

Therefore, it is not surprising that people without education - which have not gone through this socializing experience, and those with basic education - which had a much lesser exposure to this more active lifestyle - do not engage in known preventive modifiable behaviours as the more educated do (Sallis \& McKenzie, 1991). Our study evidences that the impact of formal education on risk perceptions and behaviours is not necessarily associated with formal knowledge learned per se, but rather by ingrained healthy behaviours into the lifestyle of those more educated. This suggests that although cognitive knowledge might be relevant one might have to look increasingly at social dimension of knowledge and how it is built in communities (Taggart et al., 2012).

The fact that knowledge has a social dimension is not new. Literature on social determinants shows that uneven access to health care, by vulnerable communities affects health outcomes. The results of this article help to re-discuss the pathways between knowledge and health outcomes. The way social determinants affect health outcomes is complex and many studies define different strategies of entry to this problem (De Silva et al., 2012; Maddigan, Feeny, Majumdar, Farris, \& Johnson, 2006; Mitchell, 2012; Raphael et al., 2003; Schulz et al., 2005; Walker, Gebregziabher, Martin-Harris, \& Egede, 2014; Wilkinson \& Marmot, 2003). The vulnerability may be lessened through a range of macro factors (e.g, access to healthcare), or through change of behaviours. Based on the article results, the strategies of entry are discussed with a focus on behavioural factors applied to the older populations.

With regard to other components, factual knowledge is found not to be associated with preventive behaviour, but some caution is warranted in interpreting this result. It may not necessarily indicate that factual knowledge is not relevant, but rather entail that per se it is not sufficient to change behaviour in the context of primary intervention. In this regard, the literature has strongly hinted that there are a variety of patterns that are linked to cultural and societal features. In Tanzania, it was shown that neither risk perception nor knowledge was relevant in promoting preventive behaviour because the local religious leaders did not back the use of condoms (Maswanya et al., 1999). Another study, on the student population, shows that knowledge is important but risk perceptions are not (Licht et al., 2010).

Older people facing high risk of having diabetes have higher risk perceptions but these do not translate into preventive behaviours. The literature indicates that people can be quite accurate with regard to risk perception (Hivert et al., 2009), but as indicated by health behavioural models, intention of behaviour does not translate into actual behaviours (Hivert et al., 2009). The literature has shown that risk perceptions are important to raise awareness but per se are not sufficient to induce behavioural change. The idea is that that it is an important, but not sufficient, condition and other predictors such as self-efficacy, goal planning have been identified to account for preventive behaviour (Redding, Rossi, Rossi, Velicer, \& Prochaska, 2000). However, in this context and population characterized by low literacy it is quite plausible to argue that their lack of knowledge may put several barriers in their comprehension of what the risk means. Yet, this is one of the first studies that shows empirically the association between these variables and preventive behaviours and health outcomes.

This study presents preliminary evidence of ways to assess knowledge awareness in poorly educated groups and 
older people, allowing for its application to the target group. Results suggest that our typology can be used as a useful framework to characterise knowledge of diabetes in this population. In this typology, several types of knowledge were distinguished, that ranged from more observational facts to more abstract facts and long term consequences of diabetes. By using this article's typologies of knowledge, a better understanding on how knowledge is structured in this kind of population can be achieved. This can contribute to the design of more effective prevention programs. The study showed that people score low on risk factors as opposed to the other knowledge categories (extreme complications of diabetes e pathophysiology). This goes along other studies that show the need to improve knowledge on risk factors (Zhang et al., 2012).

The non-significant correlation between educational levels, risk perceptions, and factual knowledge warrants a key result in itself. This is so for two reasons, the first is that these variables are not to be excluded but at the same time are probably less relevant for specific vulnerable populations than thought before, and for this reason alternative conceptualizations that rely on social dimensions need to be considered and fostered; the second is to underline the importance of non-statistically significant correlations in studies that can offer important insights nonetheless statistical significance issues (Scargle, 2000). This suggests that strategies based on risk perceptions are probably not the most effective strategy of entry to gain an understanding of how social determinants relate with health outcomes. This is supported by literature that has shown that risk perceptions per se are not relevant to change behaviours (Slovic, Fischhoff, \& Lichtenstein, 1982), but rather past behaviours (Nexøe et al., 1999). This raises the question about whether strategies focused on risk perceptions awareness and increased factual knowledge, which are cost effective, can really make a difference. However, one ought not to exclude behavioural strategies, but reasoning on alternative behavioural strategy more focused on the social component of knowledge.

Finally, our explorative methodology is a first step to understand components that can account for the broader association between education and preventive behaviour and risk of getting diabetes. This article results also raise the question about whether a behavioural strategy based on risk perceptions and factual knowledge can change preventive behaviours and health outcomes among the older populations. These behavioural strategies may increase awareness but the issue is whether they will lead to the desired results, which is to change behaviours and health outcomes in vulnerable and older populations.

This suggests that more observational studies of this type and experimental studies should be carried out to: 1) test whether such results are replicable in older populations, 2) to clarify the role of social knowledge, 3) to better comprehend the association of social knowledge with types of cognitive knowledge associated with this type of population. While studies that examine risk perception/knowledge with awareness are useful, it is important to examine the determinants of the ultimate outcomes, e.g., preventive behaviour and risk of getting diabetes. A more dynamic relationship between these two types of methodologies should be envisaged, coupling exploratory studies that examine determinants and more theoretical studies that examine the relationship between pairwise variables and antecedents of preventive behaviour and risk of getting diabetes.

\section{Conclusions}

As one of the first studies that empirically assesses the determinants of risk of getting diabetes and preventive behaviours in an older urban population and within a primary prevention context, it is shown that the role of formal education is important. The social dimension of formal education is found to be more influential than knowledge itself. The role of formal education seems to be connected with healthy behaviours and lifestyles (e.g., physical exercise), which seem to point out the role of context, cultural and social rules and values rather than (cognitive) knowledge per se.

It was found that education, a key component of social determinants, determines preventive behaviour and health outcomes. Addressing vulnerabilities through behavioural change is relevant. However, it might be necessary to consider whether alternative conceptualizations should be put forward as strategies for behavioural change. There is no evidence that strategies based on risk perceptions and factual knowledge affect behavioural change in older and change adverse populations.

Moreover, the fact that an association between knowledge type and education was found seems to indicate that the knowledge typology forwarded in this article can be a first step to define a conceptual framework of analysis to examine knowledge for this type of populations. However, due to the exploratory character of this study, a limitation concerns the generalization of this study's findings for other populations other than urban older populations at risk. 


\section{Acknowledgements}

We gratefully acknowledge the support of Farzaneh Eftekhary and Natália Dias for their work with the local community of older people. We also appreciate the help provided by José Pinto Ferreira regarding the interview process and involvement in stakeholder engagement.

\section{References}

Alberti, K. G. M. M., Zimmet, P., \& Shaw, J. (2007). International Diabetes Federation: a consensus on Type 2 diabetes prevention. Diabetic Medicine, 24(5), 451-463. doi:10.1111/j.1464-5491.2007.02157.x

American Diabetes Association. (2013). Economic costs of diabetes in the US in 2012. Diabetes Care, 36(4), 1033-1046.

Bailey, R. (2006). Physical education and sport in schools: A review of benefits and outcomes. Journal of School Health, 76(8), 397-401.

Bailey, R., Armour, K., Kirk, D., Jess, M., Pickup, I., Sandford, R., \& Education, B. P. (2009). The educational benefits claimed for physical education and school sport: an academic review. Research Papers in Education, 24(1), 1-27.

Baker, D. W., Wolf, M. S., Feinglass, J., Thompson, J. A., Gazmararian, J. A., \& Huang, J. (2007). Health literacy and mortality among elderly persons. Archives of Internal Medicine, 167(14), 1503.

Berkman, N. D., Sheridan, S. L., Donahue, K. E., Halpern, D. J., \& Crotty, K. (2011). Low health literacy and health outcomes: an updated systematic review. Annals of Internal Medicine, 155(2), 97-107.

Boavida, J., Almeida, J., Cardoso, S., Duarte, J., Duarte, R., \& Ferreira, H. (2012). Diabetes: Factos e Números 2011- Relatório Anual do Observatório Nacional da Diabetes. Sociedade Portuguesa de Diabetologia.

Brewer, N. T., Chapman, G. B., Gibbons, F. X., Gerrard, M., McCaul, K. D., \& Weinstein, N. D. (2007). Meta-analysis of the relationship between risk perception and health behavior: The example of vaccination. Health Psychology, 26(2), 136-145. doi:10.1037/02786133.26 .2 .136

De Silva, A. P., De Silva, S. H. P., Liyanage, I. K., Rajapakse, L. C., Jayasinghe, K. S. A., Katulanda, P., ... Wijeratne, S. (2012). Social, cultural and economical determinants of diabetes mellitus in Kalutara district, Sri Lanka: a cross sectional descriptive study. International Journal for Equity in Health, 11(1), 76.

Dillard, A. J., Ferrer, R. A., Ubel, P. A., \& Fagerlin, A. (2012). Risk perception measures' associations with behavior intentions, affect, and cognition following colon cancer screening messages. Health Psychology, 31(1), 106-113.

DiLorenzo, T., Schnur, J., Montgomery, G., Erblich, J., Winkel, G., \& Bovbjerg, D. (2006). A Model of Disease-Specific Worry in Heritable Disease: The Influence of Family History, Perceived Risk and Worry About Other Illnesses. Journal of Behavioral Medicine, 29(1), 37-49.

Edwards, M., Wood, F., Davies, M., \& Edwards, A. (2012). The development of health literacy in patients with a long-term health condition: the health literacy pathway model. BMC Public Health, 12(1), 130.

Ezzati, M., \& Riboli, E. (2012). Can noncommunicable diseases be prevented? Lessons from studies of populations and individuals. Science, 337(6101), 1482-1487.

Farmer, A., Levy, J., \& Turner, R. (1999). Knowledge of risk of developing diabetes mellitus among siblings of type 2 diabetic patients. Diabetic Medicine, 16(3), 233-237.

Ford, E. S., Merritt, R. K., Heath, G. W., Powell, K. E., Washburn, R. A., Kriska, A., \& Haile, G. (1991). Physical activity behaviors in lower and higher socioeconomic status populations. American Journal of Epidemiology, 133(12), 1246-1256.

Gornick, M. E. (2003). A decade of research on disparities in Medicare utilization: lessons for the health and health care of vulnerable men. American Journal of Public Health, 93(5), 753-759.

Greef, K., Deforche, B., Tudor-Locke, C., \& Bourdeaudhuij, I. (2010). Increasing Physical Activity in Belgian Type 2 Diabetes Patients: a Three-Arm Randomized Controlled Trial. International Journal of Behavioral Medicine, 18(3), 188-198. doi:10.1007/s12529-0109124-7

Hivert, M.-F., Warner, A. S., Shrader, P., Grant, R. W., \& Meigs, J. B. (2009). Diabetes Risk Perception and Intention to Adopt Healthy Lifest yles Among Primary Care Patients. Diabetes Care, 32(10), 1820-1822. doi:10.2337/dc09-0720

Holt, P. (2012). Type 2 diabetes in south Asian people. Nursing Standard (Royal College of Nursing (Great Britain): 1987), 26(35), 42.

Howard, D. H., Sentell, T., \& Gazmararian, J. A. (2006). Impact of health literacy on socioeconomic and racial differences in health in an elderly population. Journal of General Internal Medicine, 21(8), 857-861.

Kim, S. H. (2009). Health literacy and functional health status in Korean older adults. Journal of Clinical Nursing, 18(16), 2337-2343.

Kirsch, I. S., Educational Testing Service, P., \& And Others. (1993). Adult Literacy in America: A First Look at the Results of the National Adult Literacy Survey. (No. 0-16-041929-8). Retrieved from http://search.ebscohost.com/login.aspx?direct=true\&db=eric\&AN= ED358375\&lang=pt-br\&site=ehost-live\&scope=site

Kripalani, S., Henderson, L. E., Chiu, E. Y., Robertson, R., Kolm, P., \& Jacobson, T. A. (2006). Predictors of Medication Selfmanagement Skill in a Low-literacy Population. Journal of General Internal Medicine, 21(8), 852-856.

Lee, S.-Y. D., Bender, D. E., Ruiz, R. E., \& Cho, Y. I. (2006). Development of an Easy-to-Use Spanish Health Literacy Test. Health Services Research, 0(0), 060720074824046-??? doi:10.1111/j.1475-6773.2006.00532.x

Licht, A. S., Murphy, J. M., Hyland, A. J., Fix, B. V., Hawk, L. W., \& Mahoney, M. C. (2010). Is use of the human papillomavirus vaccine among female college students related to human papillomavirus knowledge and risk perception? Sexually Transmitted Infections, 
86(1), 74-78.

Maddigan, S. L., Feeny, D. H., Majumdar, S. R., Farris, K. B., \& Johnson, J. A. (2006). Understanding the determinants of health for people with type 2 diabetes. American Journal of Public Health, 96(9), 1649-1655.

Maina, W. K., Ndegwa, Z. M., Njenga, E. W., \& Muchemi, E. W. (2011). Knowledge, attitude and practices related to diabetes among community members in four provinces of Kenya: A cross-sectional study. Journal of Pan African Medical, 7 (2), 1, 9. Retrieved from http://www.africanjournalofdiabetesmedicine.com/articles/may_2011/Knowledge.pdf

Martín, A. R., Nieto, J. M. M., Ruiz, J. P. N., \& Jiménez, L. E. (2008). Overweight and obesity: the role of education, employment and income in Spanish adults. Appetite, 51(2), 266-272.

Maswanya, E. S., Moji, K., Horiguchi, I., Nagata, K., Aoyagi, K., Honda, S., \& Takemoto, T. (1999). Knowledge, risk perception of AIDS and reported sexual behaviour among students in secondary schools and colleges in Tanzania. Health Education Research, 14(2), 185-196.

Maty, S. C., \& Tippens, K. M. (2011). Perceived and actual diabetes risk in the Chinese and Hispanic/Latino communities in Portland, OR, USA. Diabetic Medicine, 28(6), 658-667.

Mayer-Davis, E. J., \& Costacou, T. (2001). Obesity and sedentary lifestyle: modifiable risk factors for prevention of type 2 diabetes. Current Diabetes Reports, 1, 170-176.

Mitchell, F. M. (2012). Reframing Diabetes in American Indian Communities: A Social Determinants of Health Perspective. Health \& Social Work, 37(2), 71-79. doi:10.1093/hsw/hls013

Morris, N. S., MacLean, C. D., \& Littenberg, B. (2006). Literacy and health outcomes: a cross-sectional study in 1002 adults with diabetes. BMC Family Practice, 7(1), 49.

Nabalamba, A., \& Millar, W. J. (2007). Going to the doctor. Health Rep, 18(1), 23-35.

Nexøe, J., Kragstrup, J., \& Søgaard, J. (1999). Decision on influenza vaccination among the elderly: a questionnaire study based on the Health Belief Model and the Multidimensional Locus of Control Theory. Scandinavian Journal of Primary Health Care, 17(2), 105110.

Nutbeam, D. (2000). Health literacy as a public health goal: a challenge for contemporary health education and communication strategies into the 21st century. Health Promotion International, 15(3), 259-267.

Paasche-Orlow, M. K., \& Wolf, M. S. (2007). The causal pathways linking health literacy to health outcomes. American Journal of Health Behavior, 31(Supplement 1), S19-S26.

Raphael, D., Anstice, S., Raine, K., McGannon, K. R., Rizvi, S. K., \& Yu, V. (2003). The social determinants of the incidence and management of type 2 diabetes mellitus: are we prepared to rethink our questions and redirect our research activities? Leadership in Health Services, 16(3), 10-20.

Redding, C. A., Rossi, S., Rossi, R., Velicer, W. F., \& Prochaska, O. (2000). Health behavior models. Presented at the Special Issue, Citeseer.

Reid, A. E., \& Aiken, L. S. (2011). Integration of five health behaviour models: Common strengths and unique contributions to understanding condom use. Psychology \& Health, 26(11), 1499-1520. doi:10.1080/08870446.2011.572259

Risérus, U., Willett, W. C., \& Hu, F. B. (2009). Dietary fats and prevention of type 2 diabetes. Progress in Lipid Research, 48(1), 44-51.

Robben, J. H., Knoers, N. V., \& Deen, P. M. (2006). Cell biological aspects of the vasopressin type-2 receptor and aquaporin 2 water channel in nephrogenic diabetes insipidus. American Journal of Physiology-Renal Physiology, 291(2), F257-F270.

Sabates, R., Feinstein, L., \& Britain, G. (2004). Education, Training and the take-up of preventative health care. Centre for Research on the Wider Benefits of Learning.

Salehi, L., Eftekhar, H., Mohammad, K., Tavafian, S. S., Jazayery, A., \& Montazeri, A. (2010). Consumption of fruit and vegetables among elderly people: a cross sectional study from Iran. Nutrition Journal, 9, 1-9.

Sallis, J. F., \& McKenzie, T. L. (1991). Physical education's role in public health. Research Quarterly for Exercise and Sport, 62(2), 124137.

Scargle, J. D. (2000). Publication bias: the "file-drawer" problem in scientific inference. Journal of Scientific Exploration, 14(1), 91-106.

Schillinger, D., Barton, L. R., Karter, A. J., Wang, F., \& Adler, N. (2006). Does literacy mediate the relationship between education and health outcomes? A study of a low-income population with diabetes. Public Health Reports, 121(3), 245.

Schulz, A. J., Zenk, S., Odoms-Young, A., Hollis-Neely, T., Nwankwo, R., Lockett, M., ... Kannan, S. (2005). Healthy eating and exercising to reduce diabetes: exploring the potential of social determinants of health frameworks within the context of community-based participatory diabetes prevention. Journal Information, 95(4).

Slovic, P., Fischhoff, B., \& Lichtenstein, S. (1982). Why study risk perception? Risk Analysis, 2(2), 83-93.

Sudore, R. L., Mehta, K. M., Simonsick, E. M., Harris, T. B., Newman, A. B., Satterfield, S., ... Ayonayon, H. N. (2006). Limited literacy in older people and disparities in health and healthcare access. Journal of the American Geriatrics Society, 54(5), 770-776.

Taggart, J., Williams, A., Dennis, S., Newall, A., Shortus, T., Zwar, N., ... Harris, M. F. (2012). A systematic review of interventions in primary care to improve health literacy for chronic disease behavioral risk factors. BMC Family Practice, 13(1), 49.

Tang, Y. H., Pang, S. M. C., Chan, M. F., Yeung, G. S. P., \& Yeung, V. T. F. (2008). Health literacy, complication awareness, and diabetic control in patients with type 2 diabetes mellitus. Journal of Advanced Nursing, 62(1), 74-83. doi:10.1111/j.13652648.2007.04526.x

Walker, R. J., Gebregziabher, M., Martin-Harris, B., \& Egede, L. E. (2014). Relationship between social determinants of health and processes and outcomes in adults with type 2 diabetes: validation of a conceptual framework. BMC Endocrine Disorders, 14(1), 82. 
White, S. (2008). Assessing the Nation's health literacy. Key Concepts and Findings of the National Assessment of Adult Literacy (NAAL).

Wikner, C., Gigante, B., Hellénius, M.-L., de Faire, U., \& Leander, K. (2013). The Risk of Type 2 Diabetes in Men Is Synergistically Affected by Parental History of Diabetes and Overweight. PloS One, 8(4), e61763.

Wilkinson, R. G., \& Marmot, M. G. (2003). Social determinants of health: the solid facts. World Health Organization.

Zhang, Y., Gao, W., Pang, Z., Sun, J., Wang, S., Ning, F., ... Qiao, Q. (2012). Diabetes self-risk assessment questionnaires coupled with a multimedia health promotion campaign are cheap and effective tools to increase public awareness of diabetes in a large Chinese population. Diabetic Medicine, 29(11), e425-e429. 